\title{
Indoor swimming pools, water chlorination and respiratory health
}

\author{
B. Nemery*, P.H.M. Hoet*, D. Nowak ${ }^{\#}$
}

Swimming is generally considered to be a healthy leisure activity for both the young and old. Swimming is even often advised as the most appropriate sport for asthmatic children [1-3], mainly (but probably not solely) on the grounds that inhaling moist air is less conducive to triggering exercise-induced asthma [4]. However, for obvious reasons of microbiological safety, the water of public and private swimming pools must be disinfected [5]. The most common procedure for water disinfection consists of chlorination. As with all human and technological intervention, the use of chlorine-based products to disinfect swimming water may lead to a number of unwanted effects, in particular the presence of chlorine-containing compounds in the air. Consequently, chlorination may affect the respiratory health of either those who work as swimming attendants or instructors, or those who use the pools as customers, particularly children and the general public, but also competitive swimmers. Although the issue of the chlorination of public water supplies has received considerable attention, mainly with regard to the presence of potentially carcinogenic or teratogenic chlorinated by-products $[6,7]$, the respiratory hazards of chlorinated swimming water have been less well addressed. Thus, old $[8,9]$ and even more recent [10] reports on indoor pollution do not deal with the air of chlorinated swimming pools, despite the generally obvious and readily noticeable irritant character of this type of environment, even in well-maintained pools [11].

\section{Water chlorination}

Chlorination is the most common procedure for water disinfection of public water supplies and swimming pools. Chlorine may be added to water as the gaseous form $\left(\mathrm{Cl}_{2}\right)$, which rapidly hydrolyzes to hypochlorous acid $(\mathrm{HOCl})$, or as sodium or calcium hypochlorite $\left(\mathrm{NaOCl}\right.$ or $\left.\mathrm{Ca}(\mathrm{OCl})_{2}\right)$. Hypochlorite, for disinfection, may also be produced by adding so-called hypochlorite-generating agents, such as dichloroisocyanurate, to water. In water with a $\mathrm{pH}$ between

\footnotetext{
*Laboratory of Pneumology (Unit of Lung Toxicology) and Dept of Occupational Medicine, Katholieke Universiteit Leuven, Leuven, Belgium. "\# Occupational and Environmental Medicine, Ludwig-Maximilians-University, Munich, Germany.

Correspondence: B. Nemery, Laboratory of Pneumology (Unit of Lung Toxicology), Katholieke Universiteit Leuven, Herestraat 49, B-3000 Leuven, Belgium. Fax: 32 16347124. E-mail: ben.nemery@ med.kuleuven.ac.be
}

6.5-8.5, both $\mathrm{HOCl}$ and the hypochlorite ion $\left(\mathrm{OCl}^{-}\right)$ are present.

\section{Acute hazards related to the chlorination of swimming pools}

Acute exposure to high levels of chlorine gas, resulting from explosions, leaks or malfunctioning of chlorine-disinfection installations [12-14] is a wellknown problem. The health consequences of such incidents may be more or less serious. Severe manifestations depend on the intensity of the exposure (i.e. the combination of aerial concentrations and duration of exposure) and may include laryngeal oedema, asthma attacks and chemical burns of the upper and lower airway mucosa, and even chemical pneumonitis [15]. The more frequent less serious manifestations include transient lachrymation and nasopharyngeal irritation, as well as hyperventilation. Emergency physicians should know how to deal with these casualties, which in the case of entire school parties may arrive in a large group with possibly more emotion than gravity [16]. Serious inhalation injuries must be recognized and treated accordingly, and the possibility of structural or functional sequelae, particularly reactive airways dysfunction syndrome (RADS), must be envisaged [17]. If only for medicolegal reasons, it seems wise not to discharge victims of inhalation injuries without an assessment of pulmonary function, including measurements of bronchial responsiveness and diffusion capacity or blood-gas analysis with standardized exercise. No controlled studies have evaluated the benefit of administering systemic or inhaled corticosteroids in victims of inhalation injuries, but it seems justified, based on mainly anecdotal evidence and theoretical considerations, to prevent excessive airway inflammation by inhaled corticosteroids. It is also wise to advise a follow-up of respiratory symptoms, spirometry and, if necessary, nonspecific bronchial reactivity, after 6-8 weeks.

\section{Occupational exposure to swimming-pool air}

A less well-known problem is that of the possible health effects of daily or intermittent exposures to the "normal" indoor atmosphere of swimming pools, which common experience proves to be as pungent and irritating for the eyes and upper airways, as 
some industrial environments. The typical smell of swimming-pool atmospheres is commonly attributed to "chlorine" in the air. However, recent studies have revealed, at least to the medical community, that the smell and irritant properties of swimming-pool air are mainly due to chloramines [18]. These chloramines, monochloramine $\left(\mathrm{NH}_{2} \mathrm{Cl}\right)$, dichloramine $\left(\mathrm{NHCl}_{2}\right)$ and trichloramine $\left(\mathrm{NCl}_{3}\right)$, are generated from the reaction of hypochlorite with ammonia and amino-compounds that originate from sweat and urine of the swimmers. These chloramines, and particularly the trichloramine, are quite volatile and they partition easily from the water into the air. The conditions that determine production and air levels of chloramines depend, among other factors, on the degree of water chlorination, the contamination of the water by nitrogencontaining compounds (which in turn depends on the number of bathers, as well as their behaviour and hygiene), water temperature and air recirculation [18, 19]. People working in such environments, such as pool supervisors or swimming teachers, are obviously exposed to these agents, and they may develop respiratory symptoms [19]. However, not much is known about the long-term health risks that these irritants pose to employees. No health-based occupational exposure limits seem to exist for chloramines, although proposals have been made [20]. In this issue of the European Respiratory Journal, THICKETT et al. [21] present three relatively well-documented cases of occupational asthma in swimming-pool workers. Based on the description of the patients, two of whom had a positive bronchial provocation test to chloramine in the laboratory, there is little doubt that these people had occupational asthma. However, the mechanism of the asthma in these persons remains elusive and the claim that it is due to immunological sensitization is only supported by the fact that the subjects appeared to react uniquely to reportedly low levels of trichloramine. A pure irritant effect was, therefore, considered less likely as the subjects had no increased bronchial reactivity to histamine. Irritant-induced asthma caused by chronic "low-level" exposure to irritant agents is a controversial entity for which there is still only limited epidemiological and experimental support.

Whatever the mechanism of chloramine-related asthma may be, the article by THICKETT et al. [21] is clinically important, because it serves as evidence that swimming pool-induced asthma may occur as an occupational disease. There are reasons to believe that this is not such an exceptional occurrence. Indeed, when P.S. Burge (Dept of Respiratory Medicine, Occupational Lung Diseases Unit, Heartlands Hospital, Birmingham, UK), the senior author of the article, presented one of the three cases at an interactive occupational grand round of the 1998 annual European Respiratory Society meeting in Geneva and asked "Have you seen cases of swimming-pool asthma?", $24 \%$ and $19 \%$ of the audience replied yes and maybe, respectively (more than 220 participants, $62 \%$ of whom spent $<10 \%$ of their time dealing with occupational lung disease; unpublished data).

Another reason why the report by THICKETT et al. [21] is important is that it may have implications for other types of jobs, outside swimming pools. Cleaning also involves exposure to various types of irritants, including bleach. Thus, casual and professional cleaning personnel are not only at risk of acute inhalation injury as a result of mixing incompatibilities (bleach with ammonia, bleach with acids) [22-27], but recent epidemiological studies have indicated that cleaners belong to a category of workers at higher risk of asthma [28]. Although specific reactions to cleaning agents have been described occasionally, the causes of asthma in cleaners have remained unidentified so far. Perhaps, the role of chloramines should be investigated further.

\section{Swimming and the health of swimmers}

Finally, the effect of swimming-pool atmospheres on the bathers themselves is a topic of interest. The beneficial effects of swimming in asthmatic children are generally attributed to the fact that breathing moist air is less conducive to exercise-induced bronchoconstriction than other forms of exercise [4]. However, the issue of the possible irritant exposure resulting from water chlorination have not been addressed or cannot be ascertained from publications where asthmatics have undergone swimming-training programmes $[1-3,29]$. There are anecdotal indications that asthmatic persons do not always tolerate chlorinated pools well [23, 30-32], but in general this does not appear to constitute a major problem. There are also indications that competitive swimmers have more bronchial hyperresponsiveness or asthma than other sportsmen [33, 34]. The reasons for these observations are unknown, but irritants have been suggested as a possible causal factor, although the reason could include reverse causation (asthmatics being more likely to choose swimming as a sport).

The issue of swimming and respiratory health has recently received a great deal of attention in Belgium with the highly publicized results of a cross-sectional survey of schoolchildren, which claimed that swimming in chlorinated pools represents a hazard of pulmonary damage, and could even be responsible for the recently observed increase in asthma in Western societies [35]. These conclusions were based on the observation that serum concentrations of pneumoproteins (mainly surfactant protein B (SP-B)) were elevated in children who frequently attend chlorinated swimming pools as compared to control children. Swimming attendance explained a large part of the variance in serum pneumoproteins, when other possible factors were taken into account, and there was a good dose/response relationship between serum pneumoproteins and an index of cumulative swimming-pool attendance $\left(\mathrm{h} \cdot \mathrm{week}^{-1} \cdot \mathrm{yr}\right)$, as estimated at the level of each school. Based on extensive experience [36], the researchers considered that such increased levels of serum pneumoproteins reflected increases in the alveolocapillary permeability and that this was an early indication of lung injury and risk of disease. However, no other end-points (respiratory symptoms or pulmonary function) corroborated these findings, but there was a close positive relationship between 
serum levels of SP-B and immunoglobulin-E. These findings and their interpretation as a potentially serious adverse health effect, led to some municipal and school authorities cancelling swimming lessons in primary schools. Later, experts advised the education ministers that the results of the study did not warrant such drastic measures. However, apart from its disastrous risk communication, the study did point to the need to evaluate further the possible health risks posed by chlorinated swimming pools for children and the public. There are standards for the microbiological quality of the pool water, science-based standards for the quality of the air above the water are still needed. The available information from toxicity testing in experimental animals is, as yet, not sufficient for this purpose [20,37].

Until adequate information is available, appropriate ventilation to minimize chloramine accumulation, control of water chlorination and temperature, and adequate hygiene of bathers should be enforced to reduce the irritant nature of swimming-pool environments for both those who work and those who swim there.

\section{References}

1. Fitch KD, Morton AR, Blanksby BA. Effects of swimming training on children with asthma. Arch Dis Child 1976; 51: 190-194.

2. Huang SW, Veiga R, Sila U, Reed E, Hines S. The effect of swimming in asthmatic children-participants in a swimming program in the city of Baltimore. J Asthma 1989; 26: 117-121.

3. Wardell CP, Isbister C. A swimming program for children with asthma. Does it improve their quality of life? Med J Aust 2000; 173: 647-648.

4. Bar-Or O, Inbar O. Swimming and asthma. Benefits and deleterious effects. Sports Med 1992; 14: 397-405.

5. Barwick RS, Levy DA, Craun GF, Beach MJ, Calderon RL. Surveillance for waterborne-disease outbreaks-United States, 1997-1998. Mor Mortal Wkly Rep CDC Surveill Summ 2000; 49: 1-21.

6. Cantor KP. Water chlorination, mutagenicity, and cancer epidemiology. Am J Public Health 1994; 84 : 1211-1213.

7. Nieuwenhuijsen MJ, Toledano MB, Eaton NE, Fawell J, Elliott P. Chlorination disinfection byproducts in water and their association with adverse reproductive outcomes: a review. Occup Environ Med 2000; 57: 73-85.

8. Samet JM, Marbury MC, Spengler JD. Health effects and sources of indoor air pollution. Part I. Am Rev Respir Dis 1987; 136: 1486-1508.

9. Samet JM, Marbury MC, Spengler JD. Health effects and sources of indoor pollution. Part 2. Am Rev Respir Dis 1988; 137: 221-242.

10. Strachan DP. The role of environmental factors in asthma. Br Med Bull 2000; 56: 865-882.

11. Momas I, Brette F, Spinasse A, Squinazi F, Dab W, Festy B. Health effects of attending a public swimming pool: follow up of a cohort of pupils in Paris. J Epidemiol Community Health 1993; 47: 464- 468.

12. Ploysongsang Y, Beach BC, DiLisio RE. Pulmonary function changes after acute inhalation of chlorine gas. South Med J 1982; 75: 23-26.
13. Martinez TT, Long C. Explosion risk from swimming pool chlorinators and review of chlorine toxicity. Clinical Toxicology 1995; 33: 349-354.

14. Agabiti N, Ancona C, Forastiere F, et al. Short term respiratory effects of acute exposure to chlorine due to a swimming pool accident. Occup Environ Med 2001; 58: 399-404.

15. Das R, Blanc PD. Chlorine gas exposure and the lung: a review. Toxicol Indust Health 1993; 9: 439-455.

16. Krenzelok E, Mrvos R. Chlorine/chloramine. J Toxicol Clin Toxicol 1995; 33: 355-357.

17. Nemery B. Late consequences of accidental exposure to inhaled irritants: RADS and the Bhopal disaster. Eur Respir J 1996; 9: 1973-1976.

18. Hery M, Hecht G, Gerber JM, Gendre JC, Hubert G, Rebuffaud J. Exposure to chloramines in the atmosphere of indoor swimming pools. Ann occup Hyg 1995; 39: 427-439.

19. Massin N, Bohadana AB, Wild P, Héry M, Toarmain JP, Hubert G. Respiratory symptoms and bronchial responsiveness in lifeguards exposed to nitrogen trichloride in indoor swimming pools. Occup Environ Med 1998; 55: 258-263.

20. Gagnaire F, Azim S, Bonnet P, Hecht G, Hery M. Comparison of the sensory irritation response in mice to chlorine and nitrogen trichloride. J Appl Toxicol 1994; 14: 405-409.

21. Thickett KM, McCoach JS, Gerber JM, Sadhra S, Burge PS. Occupational asthma caused by chloramines in indoor swimming-pool air. Eur Respir J 2002; 19: 827-832.

22. Reisz GR, Gammon RS. Toxic pneumonitis from mixing household cleaners. Chest 1986; 89: 49-52.

23. Fjellbirkeland L, Gulsvik A, Walloe A. Swimminginduced asthma. Tidsskr Nor Laegeforen 1995; 115: 2051-2053.

24. Mrvos R, Dean BS, Krenzelok EP. Home exposures to chlorine/chloramine gas: review of 216 cases. South Med $J$ 1993; 86: 654-657.

25. Olson KR, Shusterman DJ. Mixing incompatibilities and toxic exposures. Occup Med 1993; 8: 549-560.

26. Deschamps D, Soler P, Rosenberg N, Baud F, Gervais P. Persistent asthma after inhalation of a mixture of sodium hypochlorite and hydrochloric acid. Chest 1994; 105: 1895-1896.

27. Mapp CE, Pozzato V, Pavoni V, Gritti G. Severe asthma and ARDS triggered by acute short-term exposure to commonly used cleaning detergents. Eur Respir J 2000; 16: 570-572.

28. Kogevinas M, Anto JM, Sunyer J, Tobias A, Kromhout H, Burney $\mathrm{P}$ and European Community Respiratory Health Survey Study Group. Occupational asthma in Europe and other industrialised areas: a population-based study. Lancet 1999; 353: $1750-1754$.

29. Matsumoto I, Araki H, Tsuda K, et al. Effects of swimming training on aerobic capacity and exercise induced bronchoconstriction in children with bronchial asthma. Thorax 1999; 54: 196-201.

30. Anonymous. Wheezing at the swimming pool. Lancet 1979; 2: 1342-1343.

31. Mustchin CP, Pickering CA. "Coughing water": bronchial hyperreactivity induced by swimming in a chlorinated pool. Thorax 1979; 34: 682-683.

32. Penny PT. Swimming pool wheezing. BMJ 1983; 287: 461-462.

33. Zwick H, Popp W, Budik G, Wanke T, Rauscher H. 
Increased sensitization to aeroallergens in competitive swimmers. Lung 1990; 168: 111-115.

34. Helenius IJ, Rytilä P, Metso T, Haahtela T, Venge P, Tikkanen HO. Respiratory symptoms, bronchial responsiveness, and cellular characteristics of induced sputum in elite swimmers. Allergy 1998; 53: 346-352.

35. Carbonnelle SY, Buchet J-P, Hermans CR, Doyle IR, Bernard AM. Increased lung epithelium permeability in children regularly attending chlorinated pools. Eur Respir J 2001; 18: Suppl. 33, 186S.

36. Hermans C, Bernard A. Pneumoproteinaemia: a new perspective in the assessment of lung disorders. Eur Respir J 1998; 11: 801-803.

37. Barbee SJ, Thackara JW, Rinehart WE. Acute inhalation toxicology of nitrogen trichloride. Am Ind Hyg Assoc J 1983; 44: 145-146. 